\title{
Influência da Natureza do Rejeito Agroindustrial Fermentado por Xanthomonas axonopodis pv. Manihotis nas Propriedades das Gomas Xantana Resultantes
}

\author{
Denilson de Jesus Assis, Larissa Alves de Sousa Costa, Márcio Inomata Campos \\ Engenharia Química, Universidade Federal da Bahia
}

Carolina Oliveira de Souza, Janice Izabel Druzian

Análises Bromatológicas, Universidade Federal da Bahia

\author{
Itaciara Lazorra Nunes \\ Escola de Nutrição, Universidade Federal da Bahia
}

\author{
Francine Ferreira Padilha \\ Instituto de Tecnologia e Pesquisa, Universidade Tiradentes
}

\begin{abstract}
Resumo: Um destino para resíduos agro-industriais é usá-los como substratos fermentescíveis, diminuindo o custo na produção de produtos com alto valor agregado. Este trabalho avaliou a influência da natureza dos resíduos fermentescíveis e das cepas de Xanthomonas sobre a produção e propriedades do biopolímero resultante. A produção foi realizada em agitador orbital $\left(250 \mathrm{rpm} / 28^{\circ} \mathrm{C} / 120 \mathrm{~h}\right)$ por fermentação de sacarose (controle), glicerina residual do biodiesel e resíduo líquido de sisal. Tanto a composição do substrato como as cepas mostraram um forte efeito sobre a produção $\left(0,36-2,40 \mathrm{gL}^{-1}\right)$, viscosidade aparente $(13,73$ para $36,31 \mathrm{mPa} . \mathrm{s})$ e massa molecular $\left(2,1-5,9 \times 10^{6} \mathrm{Da}\right)$ da goma de xantana resultante, não influenciando o comportamento pseudoplástico de soluções aquosas dos biopolímeros.
\end{abstract}

Palavras-chave: Produção, viscosidade e massa molecular.

\section{Influence of the Nature Agro-Industrial Waste Fermented by Xanthomonas axonopodis pv. Manihotis the Properties of Xanthan Gums Resulting}

\begin{abstract}
A destination for agro-industrial waste is to use them as fermentation substrates. This work was aimed at evaluating the influence of the nature of the waste fermented by two strains of Xanthomonason on the biopolymer properties. The production was performed in an orbital shaker $\left(250 \mathrm{rpm} / 28^{\circ} \mathrm{C} / 120 \mathrm{~h}\right)$ by fermentation of sucrose (control), crude glycerin from biodiesel and sisal liquid waste. Both the fermented substrate composition and the strains had a strong impact on production (0.36 to 2.40 g. $\left.\mathrm{L}^{-1}\right)$, apparent viscosity (13.73 to $36.31 \mathrm{mPa}$.s) and molecular mass $\left(2.1\right.$ to $\left.5.9 \times 10^{6} \mathrm{Da}\right)$ of the resulting xanthan gum, but they did not affect the pseudoplastic behavior of aqueous biopolymers solutions.
\end{abstract}

Keywords: Production, viscosity and molecular mass.

\section{Introdução}

A goma xantana (GX) é um biopolímero extracelular produzido por diversas bactérias gram-negativas do gênero Xanthomonas. Sua estrutura primária é composta por unidades pentassacarídicas, geralmente constituída por cadeias lineares composta de duas unidades de glicose e ramificadas com duas unidades de manose e uma de ácido glucurônico ${ }^{[1,2]}$. A produção mundial de xantana em 2008 foi cerca de 40 a 50 mil t/ano, movimentando aproximadamente 270 milhões de dólares anualmente, com crescimento estimado em 5 a $10 \%$ ao ano ${ }^{[3]}$. A GX consumida no Brasil é importada, porém o país tem um grande potencial para sua fabricação, uma vez que dispõe de matéria-prima básica para sua produção ${ }^{[4]}$. $\mathrm{O}$ alto potencial de aplicação em vários segmentos industriais como espessante, geleificante, estabilizante, se deve a alta massa molecular (MM) de sua estrutura e às características peculiares que suas soluções aquosas têm de manter a viscosidade em ampla faixa de $\mathrm{pH}$ e temperatura, sendo estas propriedades correlacionadas a composição e conformação química do biopolímero ${ }^{[5,6]}$.

A MM, a composição e as ramificações da GX dependem da cepa de Xanthomonas ${ }^{[7-9]}$, da composição do meio fermentativo e das condições operacionais da fermentação ${ }^{[10-14]}$. Devido ao mercado crescente, estudos têm sido conduzidos objetivando a seleção de cepas altamente produtoras, o melhoramento das cepas e dos meios de cultivo e dos processos de fermentação, extração e purificação de $\mathrm{GX}^{[15,16]}$. Comercialmente a GX é obtida por fermentação de glicose de milho suplementada com muitos nutrientes ${ }^{[17]}$. Entretanto, fontes alternativas como

Autor para correspondência: Carolina Oliveira de Souza, Departamento de Análises Bromatológicas, Faculdade de Farmácia, Universidade Federal da Bahia - UFBA, Rua Barão de Geremoabo, s/n, Ondina, CEP 40171-970, Salvador, BA, Brasil,

e-mail: carolinaods@hotmail.com 
rejeitos agroindustriais têm sido estudados como fontes de carbono, visando além da redução dos problemas ambientais gerados pelo descarte, à diminuição nos custos de produção da xantana, uma vez que a composição dos mesmos, exige menor suplementação quando comparado ao meio fermentativo sintético ${ }^{[17-20]}$.

A glicerina bruta é um subproduto da indústria do biodiesel, é produzido a partir da reação de transesterificação de um óleo ou gordura com um álcool na presença de catalisadores. É um resíduo gerado em grandes volumes $(10 \%)$ na produção de biodiesel ${ }^{[21,22]}$ e a estimativa até 2013 é de um excedente deste rejeito na ordem de $150 \mathrm{mil}$ ton/ano no mercado brasileiro. No Brasil, o sisal (Agave sisalana) é um produto de grande interesse econômico e cultivado em larga escala em alguns estados do nordeste brasileiro. Da folha do sisal aproveitam-se apenas as fibras, que são usadas na fabricação de cordas, tapetes, entre outras, sendo a parte aquosa e o bagaço que representam $96 \%$ do total, são considerados rejeitos ${ }^{[23]}$.

Há, portanto, necessidade de implementar sistemas de aproveitamento desses rejeitos através do desenvolvimento de novos produtos e ao mesmo tempo reduzir o custo da produção de GX. Considerando o exposto, o objetivo deste estudo foi avaliar a influência de diferentes substratos alternativos fermentescíveis oriundos de rejeitos agroindustriais, na produção, no grau de conversão, nas propriedades reológicas e MM das GX produzidas pelas cepas Xanthomonas axonopodis $p v$. manihotis 1182 e 356.

\section{Experimental}

\section{Microrganismos e manutenção}

As cepas de Xanthomonas axonopodis pv. manihotis 1182 e 356, oriundas da Coleção de Culturas de Fitobactérias do Instituto Biológico (IBSBF), CampinasSP foram mantidas em placas de Petri contendo meio YM (Yeast Malt) acrescido de 2,0\% de ágar puro ao meio YM padrão $(0,3 \%$ de extrato de malte, $0,3 \%$ de extrato de levedura, $0,5 \%$ de peptona bacteriológica, $1,0 \%$ de glicose) e água destilada (m/v), armazenadas sob refrigeração e repicadas periodicamente.

\section{Rejeitos agroindustriais}

A glicerina residual do biodiesel (GRB) foi doada pela Planta-piloto de Biodiesel da Universidade Estadual de Santa Cruz, Ilhéus - BA e o resíduo liquido de sisal (RLS) foi doado pela APAEB - Associação de Produtores de Sisal de Valente/BA.

\section{Composição centesimal dos rejeitos agroindustriais}

Os resíduos foram avaliados em termos de lipídios totais (Bligh \& Dyer) ${ }^{[24]}$, umidade, cinzas e proteína bruta $(\mathrm{AOAC})^{[25]}$. O teor de carboidratos foi calculado pela diferença entre 100 e a soma dos percentuais de umidade, proteína, lipídios totais e cinzas. As análises foram realizadas em triplicatas.

\section{Produção da GX}

A obtenção da GX consistiu das seguintes etapas: repicagem, preparação do inóculo, produção e separação da goma.

\section{Repicagem e Preparação do inóculo}

Para a repicagem foi utilizado o Ágar YM, autoclavado (121 ${ }^{\circ} \mathrm{C} / 15 \mathrm{~min}$.), solidificado em placa de Petri com uma alçada da cultura estoque na superfície do meio, incubadas em estufa bacteriológica por $48 \mathrm{~h}$ a $28{ }^{\circ} \mathrm{C}$.

Para a inoculação em $50 \mathrm{~mL}$ do meio YM padrão autoclavado (121 ${ }^{\circ} \mathrm{C} / 15 \mathrm{~min}$.) em Erlenmeyer (250 mL), foi adicionado uma alçada da cultura repicada e incubado a $28{ }^{\circ} \mathrm{C} / 180 \mathrm{rpm} / 24 \mathrm{~h}$, em agitador rotativo (Tecnal, mod. TE-424).

\section{Produção e Extração da GX}

Para a produção de GX foram transferidos $20 \%$ do inóculo $\left(\approx 10^{11} \mathrm{UFC} / \mathrm{mL}\right)$ para Erlenmeyers $(250 \mathrm{~mL})$ contendo $80 \mathrm{~mL}$ do meio fermentativo elaborado com $2,0 \%$ de substrato (GRB ou RLS) ou sacarose (controle) suplementado com $0,01 \%$ de uréia e $0,1 \%$ de $\mathrm{KH}_{2} \mathrm{PO}_{4}$. A fermentação aeróbica transcorreu em agitador rotativo (Shaker Tecnal, TE-424) a $28{ }^{\circ} \mathrm{C}, 250 \mathrm{rpm}$ por $120 \mathrm{~h}^{[4]}$. Os caldos fermentativos contendo GX foram centrifugados a $5{ }^{\circ} \mathrm{C}$ e $9625 x g$ (Eppendorf, 5702R) por $30 \mathrm{~min}$. para remoção celular. Para a precipitação da goma foi adicionado álcool etílico comercial (3 partes de álcool para 1 de meio fermentado). O biopolímero obtido foi seco em estufa a $35 \pm 2{ }^{\circ} \mathrm{C}$ e moído com auxílio de gral com pistilo, para a determinação gravimétrica da produção (g.L $\left.\mathrm{L}^{-1}\right)$, além de viscosidade aparente e MM.

\section{Massa Molecular}

A determinação da MM das GX obtidas por fermentação da sacarose e dos substratos alternativos foi realizada por GPC CLAE-IR (Perkin Elmer Serie 200), com colunas SB 803, 804, 805, 806 em série, tendo como fase móvel solução aquosa de nitrato de sódio $(0,5 \% \mathrm{~m} / \mathrm{v})$ a um fluxo de $1,0 \mathrm{~mL} / \mathrm{min}$. Foram injetados $80 \mu \mathrm{L}$ das soluções aquosas $(0,5 \% \mathrm{~m} / \mathrm{v})$ de 10 padrões de dextrana (American Polymer Standards) de diferentes MM (102.000 a 5.900.000) e das GX obtidas por fermentação da sacarose, GRB e RLS. Os valores das MM foram obtidos a partir de uma curva de calibração ( $\log$ Massa Molecular x Tempo de Retenção) dos padrões de dextrana.

\section{Consumo dos substratos fermentescíveis à GX}

Soluções aquosas dos padrões dos monômeros que compõem a GX $(0,3 \% \mathrm{~m} / \mathrm{v}$ de glicose, manose e ácido glucurônico), bem como, das soluções de GX Sigma (Sigma Aldrich, USA) $(0,3 \% \mathrm{~m} / \mathrm{v})$, e das soluções dos substratos antes da fermentação e depois de 120 horas de fermentação, foram separadas por GPC CLAE-IR, nas mesmas condições cromatográficas descritas para a determinação da MM. O percentual de consumo de cada substrato fermentescível foi calculado pela redução percentual das respectivas áreas dos picos obtidos antes 
e no final da fermentação. Os percentuais de monômeros não polimerizados pelas cepas no final do processo fermentativo foi avaliado pelo surgimento dos picos de glicose, manose e ácido glucurônico livres nas soluções aquosas das GX cromatografadas.

\section{Viscosidade aparente}

A viscosidade aparente das GX foi medida em função da taxa de cisalhamento em um viscosímetro Haake Rheotest (Medingen 2.1), com dispositivo de cilindros concêntricos, acoplado a um banho-maria. Para a análise foram requeridos $25 \mathrm{~mL}$ das soluções aquosas de GX $(0,25 \% \mathrm{~m} / \mathrm{v})$, preparadas e mantidas sob refrigeração a $4{ }^{\circ} \mathrm{C}$ por $12 \mathrm{~h}$ antes de se proceder às medições. A viscosidade aparente das soluções aquosas de xantana foi determinada entre 25 a $85^{\circ} \mathrm{C}$ e taxa de cisalhamento de 25 a $1000 \mathrm{~s}^{-1}$. O efeito da taxa de cisalhamento na viscosidade das soluções dos biopolímeros foi descrito pelo modelo cinético de Ostwald-de Waele: $\mu=\mathrm{K} .(\gamma)^{\mathrm{n}-1}$, onde K é o índice de consistência, $\mathrm{n}$ é o índice do comportamento do fluxo, $\mu$ é a viscosidade aparente e $\gamma$, a taxa de cisalhamento.

\section{Resultados e Discussão}

\section{Composição centesimal dos substratos alternativos e produção de GX}

A composição do substrato fermentescível é importante, uma vez que os nutrientes e micronutrientes que o constitui irão interferir, tanto na reprodução celular das bactérias de Xanthomonas, quanto na produção da GX resultante. A presença de quantidades satisfatórias de nutrientes e micronutrientes nos substratos fermentescíveis pode ser um fator importante na redução dos custos de produção da GX, uma vez que a matériaprima fermentescível na produção comercial é responsável por até $30 \%$ dos custos na obtenção do biopolímero ${ }^{[26-28]}$. A caracterização da GRB, bem como, do RLS, foram realizadas a fim de determinar os constituintes nutricionais presentes nos substratos alternativos, avaliando assim, a possibilidade de serem usados como fontes de carbono e de nitrogênio, além de outros macro e micronutrientes.
A GRB e o RLS apresentaram altos teores de umidade, $53,50 \%$ e $93,58 \%$ respectivamente (Tabela 1 ).

A relação $\mathrm{C}: \mathrm{N}$ do meio fermentativo exerce uma influência direta na produção de $\mathrm{GX}$. A relação $\mathrm{C}: \mathrm{N}$ foi duas vezes maior no RLS quando comparado a GRB (Tabela 1). Nery et al. ${ }^{[4]}$ relatam $1,5: 1$ para soro de leite, Brandão et al. ${ }^{[29]}$ relatam 22:1 para caldo de cana e Brandão et al. ${ }^{[15]} 8: 1$ para soro de mandioca, quando empregados como substratos alternativos para a produção de GX. Um valor relativamente elevado da relação C:N favorece a produção de xantana ${ }^{[30]}$, enquanto meios contendo elevado teor de fonte de carbono e baixo teor de nitrogênio favorece o acúmulo de polímero ${ }^{[27-31]}$. Nitschke et al. ${ }^{[32]}$ relatam que a GX é produzida como metabólito secundário e propuseram a dissociação do processo em duas fases distintas: a fase de crescimento, onde maior concentração de nitrogênio é requerida para o crescimento celular e a fase de produção de polímero, onde maior concentração de carbono é necessária, visando o acúmulo de produto.

Em geral os processos industriais procuram utilizar meios que disponibilizem condições tanto para o crescimento celular, como para o acúmulo de $\mathrm{GX}^{[5]}$. García-Ochoa et al. ${ }^{[26]}$ e Rosalam e England ${ }^{[33]}$, afirmam que a produção de GX é influenciada por diversos fatores, dentre estes destacam-se o microrganismo utilizado, o tempo de fermentação e principalmente o substrato do meio fermentativo e a composição do mesmo.

A GRB e o RLS apresentam composição química satisfatória para serem utilizados como substratos de processos fermentativos, podendo ser utilizados para produzir GX. Os valores da produção de GX obtidas pelas cepas de Xanthomonas 1182 e 356 por fermentação da sacarose (controle) e dos substratos alternativos a 2,0\% (GRB e RLS) suplementados com uréia $(0,01 \%(\mathrm{~m} / \mathrm{v}))$ e $\mathrm{KH}_{2} \mathrm{PO}_{4}(0,1 \%(\mathrm{~m} / \mathrm{v}))$, em shaker a $28{ }^{\circ} \mathrm{C}, 250 \mathrm{rpm}$ por $120 \mathrm{~h}$, constam na Tabela 1 . A fermentação dos substratos alternativos e do controle com as duas cepas de Xanthomonas resultam em diferentes produções de GX. Independente das cepas as maiores produções foram obtidas com a fermentação do RLS, que apresenta a maior relação C:N (Tabela 1). Em comparação com o controle, a cepa 1182 ao fermentar RLS promove um aumento de $93,55 \%$ na produção de GX enquanto que

Tabela 1. Composição centesimal dos substratos fermentescíveis e produções de gomas xantana obtidas após 120 horas de fermentação a $28^{\circ} \mathrm{C}$ e $250 \mathrm{rpm}$ pelas cepas 1182 e 356 .

\begin{tabular}{lccr}
\hline \multicolumn{1}{c}{ Parâmetros } & \multicolumn{3}{c}{ Composição (\%) } \\
\cline { 2 - 4 } & Sacarose* & GRB & RLS \\
\hline Umidade & - & $53,50 \pm 0,01$ & $0,58 \pm 0,01$ \\
Cinzas & - & $3,40 \pm 0,01$ & $0,23 \pm 0,01$ \\
Proteína Bruta & - & $2,71 \pm 0,03$ & $0,37 \pm 0,01$ \\
Lipídios Totais & - & $6,70 \pm 0,02$ & $5,27 \pm 0,01$ \\
Carboidratos & 100 & $33,69 \pm 0,02$ & $22: 1$ \\
C:N & - & $12: 1$ & $2,40 \pm 0,20$ \\
Goma Xantana (g.L-1) & & & $1,42 \pm 0,20$ \\
GX1182 & $1,24 \pm 0,30$ & $0,65 \pm 0,10$ & $0,36 \pm 0,07$ \\
GX 356 & $1,08 \pm 0,30$ & .
\end{tabular}

*Sacarose foi usada como substrato controle. GRB: Glicerina Residual do Biodísel e RLS: Resíduo Líquido de Sisal) como substratos alternativos. GX 1182 : Goma Xantana produzida pela cepa 1182; GX 356: Goma Xantana produzida pela cepa 356. 
a cepa 356, este percentual é de $31,48 \%$ (Tabela 1). A cepa Xanthomonas axonopodis 1182 foi mais produtiva, independente do substrato testado, quando comparada com a cepa Xanthomonas axonopodis 356, indicando uma maior capacidade de adaptação da primeira aos meios alternativos. Rottava et al. ${ }^{[34]}$ ao testar 10 cepas de Xanthomonas para a produção de GX a partir do meio composto de sacarose suplementado com 7 sais, relatam valores de 5,90 a 9,67 g. $\mathrm{L}^{-1}$, sendo o limite superior obtido com a cepa 1182, indicando também que esta cepa tem maior capacidade de adaptação, além de identificar a influência da composição de sais do meio fermentativo na produção de GX. Portanto, tanto a composição de macronutrientes dos rejeitos (Tabela 1) como as cepas exercem grande influência na produção $\left(0,36-2,40\right.$ g.L $\mathrm{L}^{-1}$, Tabela 1) de GX, entretanto a utilização de substratos alternativos pode representar uma diminuição substancial dos custos de produção do biopolímero aliada à possibilidade de destinação do rejeito.

\section{Massa molecular, consumo dos substratos, viscosidade aparente e comportamento reológico}

Dez padrões de dextrana de diferentes MM com intervalo de 102.000 Da à 5.900.000 Da foram separados por GPC CLAE-IR, resultando tempos de retenção de 31,56 à 26,43 minutos. A curva de calibração obtida pelo $\log$ da $M M$ em função do tempo de retenção de cada padrão de dextrana apresentou $R^{2}=0,97$ $(y=-0,301 x+14,56)$.

As separações cromatográficas (GPC CLAE-IR) das soluções padrões de GX Sigma, dos padrões de glicose, manose, ácido glucurônico e sacarose, e das soluções das GX produzidas com as duas cepas por fermentação de sacarose, GRB e RLS estão apresentados na Figura 1. As soluções dos substratos antes de fermentar também estão apresentadas na mesma figura, e os tempos de retenção dos picos envolvidos em todas as separações cromatográficas e os respectivos percentuais das áreas na Tabela 2 .

A separação GPC CLAE-IR mostra que a MM da GX Sigma (padrão) é superior a 5,90 × $10^{6} \mathrm{Da}$, representando $62,20 \%$ do total de área. Todas as GX produzidas com os substratos alternativos apresentaram duas frações do polímero com diferentes MM (> 5,90 × $10^{6} \mathrm{Da}$, e 2,10-3,10 × 106 Da) (Figura 1, Tabela 2).

Considerando que as condições fermentativas, as concentrações de substratos e a suplementação dos meios foram exatamente iguais, pode-se correlacionar os percentuais de áreas dos produtos gerados ao final da fermentação, obtidos por GPC CLAE-IR, para comparação da eficiência de consumo dos substratos, produção de GX pelas cepas e caracterização das mesmas.

A fermentação de sacarose (controle) pela cepa 1182 (Figura 1B, Tabela 2) resultou em consumo total da fonte de carbono, ao contrario da cepa 356 que no final da fermentação permaneceu com $25,99 \%$ da fonte de carbono. Do total de produtos gerados pela cepa 1182 , $80,83 \%$ da área é de GX (56,41\% com MM superior á $5,90 \times 10^{6}$ Da e $24,42 \%$ com $\left.3,10 \times 10^{6} \mathrm{Da}\right)$, e $19,17 \%$ é de compostos não identificados. A cepa 356 resultou em percentuais menores de GX com MM média superior á $5,90 \times 10^{6} \mathrm{Da}(33,09 \%)$ e de $2,80 \times 10^{6} \mathrm{Da}(17,69 \%)$, e no final da fermentação além da sacarose constatou-se a presença de $23,23 \%$ da área total dos produtos de compostos não identificados (Tabela 2). Portanto, os resultados de GPC CLAE-IR mostram que a cepa 1182 consome mais a sacarose, resultando em maior produção de GX (Tabela 1), com maior MM média (Tabela 2), além de apresentar maiores limites de distribuição da MM como pode ser observado no cromatograma da Figura 1B. As pequenas diferenças nas MMs podem justificar as viscosidades aparente das soluções aquosas das gomas resultantes de ambas as cepas por fermentação da sacarose (Tabela 2).

$\mathrm{Na}$ fermentação da GRB constatou-se que apesar da baixa produção de GX (Tabela 1), ambas as cepas consumiram totalmente o substrato (Figura 1C, Tabela 2), podendo indicar que grande parte deste deve ter sido destinado à manutenção celular. Do total de área dos produtos gerados pela cepa 1182 por fermentação deste rejeito, $66,24 \%$ é GX $(8,40 \%$ com MM média superior á $5,90 \times 10^{6}$ Da e $57,84 \%$ de $3,10 \times 10^{6} \mathrm{Da}$ ), além de $8,33 \%$ de glicose ou manose, $3,98 \%$ de ácido glucurônico não polimerizados, e $21,45 \%$ de produtos não identificados. Dos produtos da cepa 356, um percentual maior é de GX $\left(85,07 \%\right.$ com MM média superior a 5,90 × $\left.10^{6} \mathrm{Da}\right)$, além de $2,07 \%$ de ácido glucurônico, 3,96\% como glicose ou manose não polimerizados e $8,90 \%$ de compostos não identificados. O maior percentual de GX com maior MM produzida pela cepa 356 a partir de GRB pode justificar a maior viscosidade aparente das soluções aquosas deste polímero $\left(0,25 \% \mathrm{~m} / \mathrm{v}, 25 \mathrm{~s}^{-1}, 25^{\circ} \mathrm{C}\right)$ quando comparado à cepa 1182 (Tabela 2 ).

A separação cromatográfica por GPC CLAE-IR mostra que o RLS antes de fermentar contém 0,36 g.L. ${ }^{-1}$ $(72,35 \%)$ de sacarose, 0,04 g.L $L^{-1}(9,72 \%)$ de glicose ou manose, além de $17,93 \%$ de composto não identificado (Figura 1D, Tabela 2). Após 120 h de fermentação deste substrato pela cepa 1182 , verificou-se que do total da área dos produtos, $73,51 \%$ é GX $(72,01 \%$ com MM média acima de $5,90 \times 10^{6}$ Da e $1,50 \%$ com $\left.2,70 \times 10^{6} \mathrm{Da}\right)$, além de $1,55 \%$ de sacarose, $1,04 \%$ ácido glucurônico e $5,80 \%$ glicose ou manose, ou seja, $2,14 \%$ da sacarose presente no início do processo e $59,67 \%$ de glicose ou manose ainda se encontram presente ao final da fermentação. As cepas 1182 e 356 consumiram 79,24\% e $63,10 \%$ dos componentes do RLS, respectivamente, justificando os resultados de produção de GX (Tabela 1). Entretanto, se comparado a GX produzida pela cepa 1182, menor percentual da GX apresenta MM média acima de $5,90 \times 10^{6} \mathrm{Da}(53,55 \%)$ e percentual similar de $2,10 \times 10^{6} \mathrm{Da}(1,58 \%)$. Dos componentes do RLS não convertidos pela $356,8,53 \%$ da área é sacarose, $12,54 \%$ glicose ou manose e $23,80 \%$ compostos não identificados. A diferença da viscosidade aparente das soluções aquosas das GX produzidas pelas duas cepas a partir de RLS também pode estar relacionada às diferenças nas MMs (Tabela 2), e apesar dos componentes do RLS não terem sido totalmente consumidos ao final da fermentação (Tabela 2), ambas as cepas produziram maior quantidade de GX com este rejeito (Tabela 1). 
Todas as GX produzidas apresentaram viscosidades aparente inferiores (13,73 a 36,31 mPa.s) a da GX Sigma (250 mPa.s) que é produzida em escala fermentativa maior interferindo nas propriedades do polímero. $\mathrm{O}$ limite superior de viscosidade foi apresentado pela GX produzida com a cepa 356 a partir da fermentação de GRB (Tabela 2). A viscosidade da GX produzida com sacarose

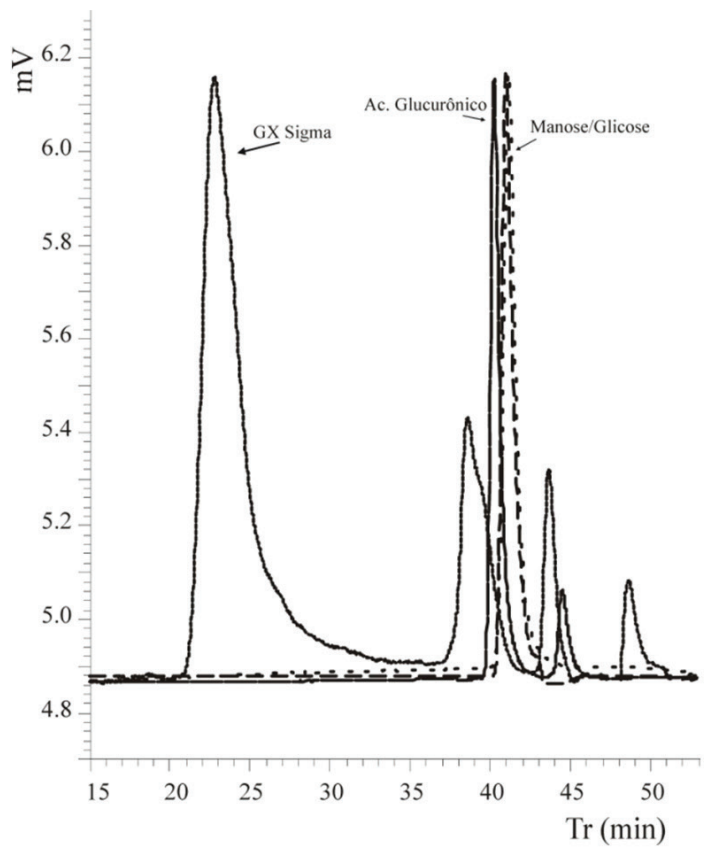

(a)

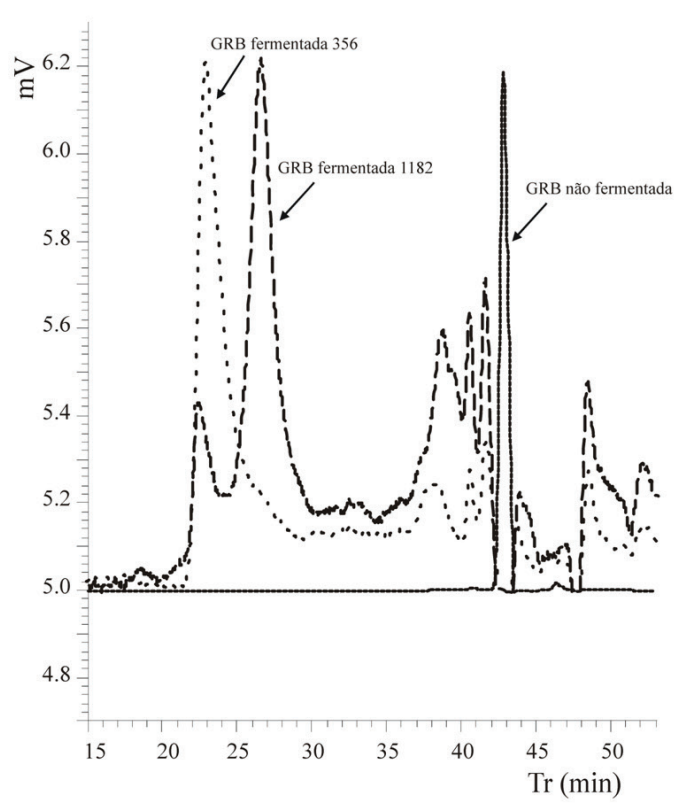

(c) (controle) foi de 21,43 mPa.s (1182) e 27,75 mPa.s (356), valores similares aos das GX produzidas com os substratos alternativos.

A massa molecular e a viscosidade das GX dependem da associação entre as moléculas do biopolímero, que por sua vez depende também das cepas que irão realizar a bioconversão, do substrato utilizado, da composição

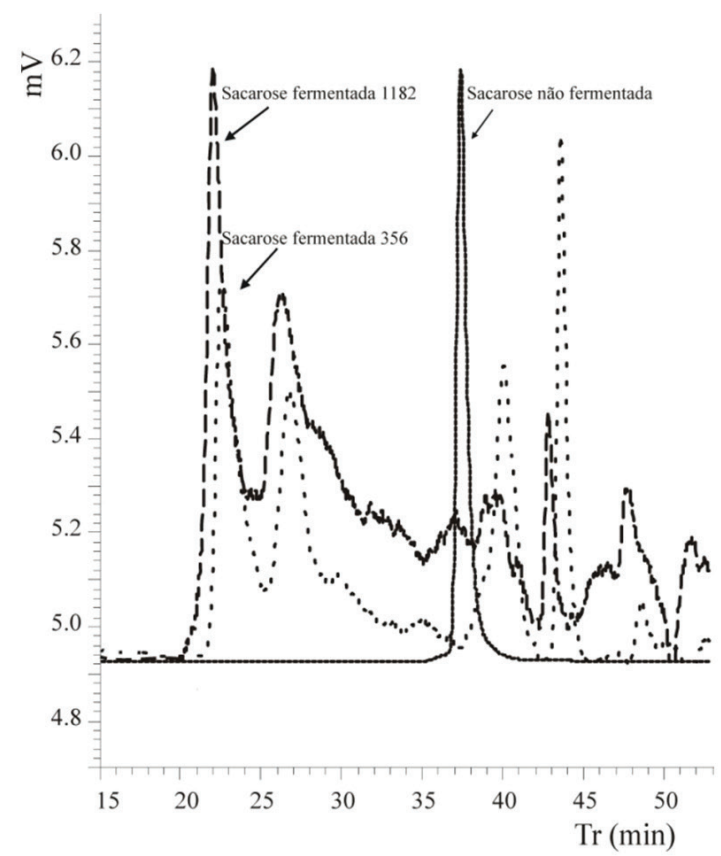

(b)

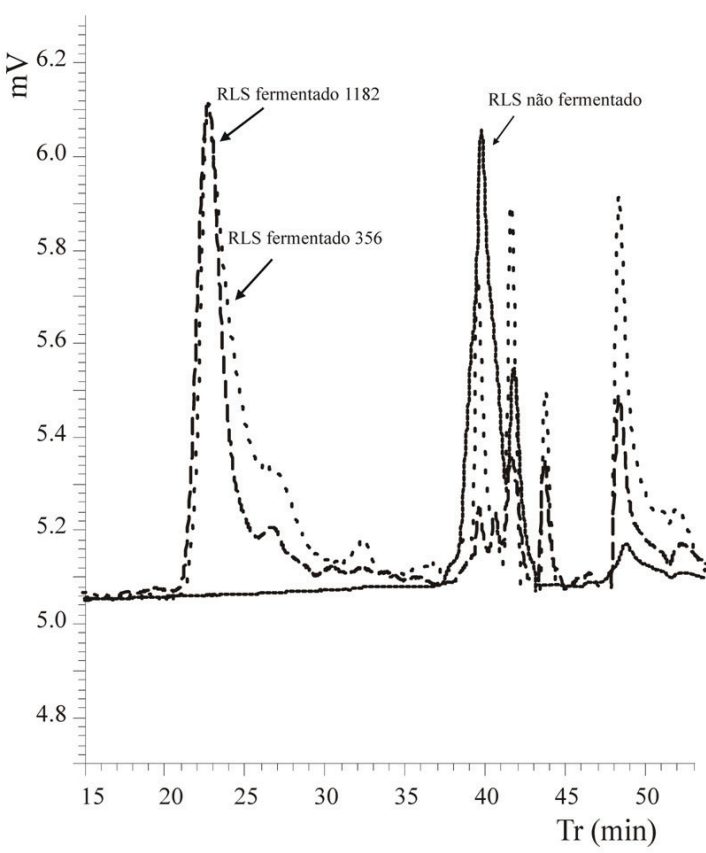

(d)

Figura 1. Cromatogramas GPC CLAE-IR dos substratos, dos monômeros e das gomas xantana (GX). (A) GX Sigma, Manose, Glicose, Ácido Glucurônico; (B) Sacarose fermentada (1182 e 356) e não fermentada; (C) GRB fermentada (1182 e 356) e não fermentada e (D) RLS fermentado (1182 e 356) e não fermentado. 
do meio fermentativo e da variação das condições operacionais utilizadas no processo de fermentação ${ }^{[9,26,35]}$. A alta MM da GX e a estrutura terciária conferem às soluções aquosas do biopolímero a propriedade de tornar-se mais ou menos viscosa ${ }^{[36]}$.

O comportamento pseudoplástico das soluções das diferentes GX foi confirmado através do ajuste do modelo de Ostwald-de-Waele aos dados experimentais, a partir da regressão de potência. A pseudoplasticidade indica que o índice de consistência $(K)$ diminui ao aumentar a temperatura, enquanto que o índice de fluxo (n) aumenta com o incremento da temperatura (Figura 2). Os parâmetros reológicos das gomas produzidas com as duas cepas de Xanthomonas e os três substratos são mostrados na Tabela 3

As soluções de GX obtidas com os substratos estudados se comportaram de acordo com o modelo descrito, onde todos os valores de $n$ foram menores que uma unidade, o que confirma um comportamento pseudoplástico (Tabela 3). O valor de $\mathrm{K}$ indica o grau de resistência do fluido diante do escoamento, assim, quanto maior o valor de $K$ mais viscoso será o fluido, ou

Tabela 2. Tempos de retenção médio, áreas dos picos (\%) e massa molecular média (Da) dos compostos separados por GPC CLAE-IR e viscosidade aparente $(\mu)$ das gomas xantana.

\begin{tabular}{|c|c|c|c|c|c|c|c|c|c|c|c|c|c|}
\hline \multirow{2}{*}{\multicolumn{2}{|c|}{$\begin{array}{c}\text { Compostos separados } \\
\text { por GPC CLAE-IR }\end{array}$}} & \multicolumn{10}{|c|}{ Área dos picos (\%) e MM (Da) } & \multirow{3}{*}{$\begin{array}{c}\text { Área } \\
\text { Total } \\
\text { GX } \\
(\%)\end{array}$} & \multirow{3}{*}{$\begin{array}{c}\mu \\
(\mathbf{m P a} \text { ).s })\end{array}$} \\
\hline & & \multicolumn{2}{|c|}{$\begin{array}{c}\text { Área GX, \% } \\
\text { (MM, Da) }\end{array}$} & \multicolumn{8}{|c|}{$\begin{array}{l}\text { Padrões de monômeros }{ }^{1} \text {, substratos fermentescíveis }{ }^{2}, \text { compostos } \\
\text { não identificados }{ }^{3} \text {, e monômeros não polimerizados }{ }^{4}(\%)\end{array}$} & & \\
\hline & r (min.) & 22,80 & 26,60 & $38,60^{3}$ & $39,80^{2}$ & $40,84^{1,4}$ & $41,80^{1,4}$ & $43,02^{2}$ & $43,70^{3}$ & $48,61^{3}$ & $52,34^{3}$ & & \\
\hline \multirow[t]{3}{*}{ Padrões } & $\begin{array}{l}\text { Ácido } \\
\text { Glucurônico }{ }^{1,4}\end{array}$ & - & - & - & & 100 & - & - & - & - & - & - & - \\
\hline & $\begin{array}{l}\text { Glicose/ } \\
\text { Manose }^{1,4}\end{array}$ & - & - & - & - & - & 100 & - & - & - & - & - & - \\
\hline & GX Sigma & $\begin{array}{c}62,20 \\
\left(>5,90 \times 10^{6}\right)\end{array}$ & - & 20,20 & - & - & - & - & 8,20 & 9,40 & - & 62,20 & 265,00 \\
\hline \multirow[t]{3}{*}{ Sacarose } & $\begin{array}{l}\text { Não } \\
\text { fermentada }{ }^{2}\end{array}$ & - & - & - & 100 & - & - & - & - & - & - & - & - \\
\hline & $\begin{array}{l}\text { Fermentada } \\
1182\end{array}$ & $\begin{array}{c}56,41 \\
\left(>5,90 \times 10^{6}\right)\end{array}$ & $\begin{array}{c}24,42 \\
\left(3,10 \times 10^{6}\right)\end{array}$ & - & - & - & - & - & 10,95 & 5,46 & 2,76 & 80,83 & 21,43 \\
\hline & $\begin{array}{l}\text { Fermentada } \\
356\end{array}$ & $\begin{array}{c}33,09 \\
\left(>5,90 \times 10^{6}\right)\end{array}$ & $\begin{array}{c}17,69 \\
\left(2,80 \times 10^{6}\right)\end{array}$ & - & 25,99 & - & - & - & 21,40 & 1,83 & - & 50,78 & 27,75 \\
\hline \multirow[t]{3}{*}{ GRB } & $\begin{array}{l}\text { Não } \\
\text { fermentada }^{2}\end{array}$ & - & - & - & - & - & - & 100 & - & - & - & - & - \\
\hline & $\begin{array}{l}\text { Fermentada } \\
1182\end{array}$ & $\begin{array}{c}8,40 \\
\left(>5,90 \times 10^{6}\right)\end{array}$ & $\begin{array}{c}57,84 \\
\left(3,10 \times 10^{6}\right)\end{array}$ & 9,20 & - & 3,98 & 8,33 & - & 5,58 & 6,67 & - & 66,24 & 18,20 \\
\hline & $\begin{array}{l}\text { Fermentada } \\
356\end{array}$ & $\begin{array}{c}85,07 \\
\left(>5,90 \times 10^{6}\right)\end{array}$ & - & 4,15 & - & 2,07 & 3,96 & - & 1,04 & 3,71 & - & 85,07 & 36,31 \\
\hline \multirow[t]{3}{*}{ RLS } & $\begin{array}{l}\text { Antes } \\
\text { fermentação }\end{array}$ & - & - & - & 72,35 & - & 9,72 & - & - & 17,93 & - & - & - \\
\hline & $\begin{array}{l}\text { Fermentada } \\
1182\end{array}$ & $\begin{array}{c}72,01 \\
\left(>5,90 \times 10^{6}\right)\end{array}$ & $\begin{array}{c}1,50 \\
\left(2,70 \times 10^{6}\right)\end{array}$ & - & 1,55 & 1,04 & 5,80 & - & 4,69 & 13,41 & - & 73,51 & 35,85 \\
\hline & $\begin{array}{l}\text { Fermentada } \\
356\end{array}$ & $\begin{array}{c}53,55 \\
\left(>5,90 \times 10^{6}\right)\end{array}$ & $\begin{array}{c}1,58 \\
\left(2,10 \times 10^{6}\right)\end{array}$ & - & 8,53 & - & 12,54 & - & 7,97 & 15,83 & - & 55,13 & 13,73 \\
\hline
\end{tabular}

Tr: Tempos de retenção médio; GX: Goma Xantana; GRB: Glicerina Residual Bruta; RLS: Resíduo Liquido de Sisal; $\mu$ : Viscosidade aparente a $0,25 \%(\mathrm{~m} / \mathrm{v}), 25 \mathrm{~s}^{-1}$, e $25{ }^{\circ} \mathrm{C} ;{ }^{1}$ : Padrões de monômeros; ${ }^{2}$ : substratos fermentescíveis; ${ }^{3}$ : compostos não identificados; ${ }^{4}$ : monômeros não polimerizados.

Tabela 3. Parâmetros reológicos das gomas xantana produzidas com as cepas de Xanthomonas e os substratos: Glicerina Residual do Biodiesel (GRB), Resíduo Líquido de Sisal (RLS) e Sacarose.

\begin{tabular}{|c|c|c|c|c|c|c|c|c|c|c|}
\hline \multirow[t]{2}{*}{ Cepas } & \multirow[t]{2}{*}{$\mathbf{T}\left({ }^{\circ} \mathbf{C}\right)$} & \multicolumn{3}{|c|}{ GRB } & \multicolumn{3}{|c|}{ RLS } & \multicolumn{3}{|c|}{ Sacarose } \\
\hline & & $\mathbf{n}$ & $\mathbf{K}$ & $\mathbf{R}^{2}$ & $\mathbf{n}$ & $\mathbf{K}$ & $\mathbf{R}^{2}$ & $\mathbf{n}$ & $\mathbf{K}$ & $\mathbf{R}^{2}$ \\
\hline \multirow[t]{4}{*}{1182} & 25 & 0,66 & 53,1 & 0,99 & 0,54 & 156,5 & 0,99 & 0,58 & 82,1 & 0,98 \\
\hline & 45 & 0,69 & 42,3 & 0,99 & 0,56 & 119,4 & 0,99 & 0,62 & 70,3 & 0,99 \\
\hline & 65 & 0,71 & 24,6 & 0,99 & 0,60 & 97,9 & 0,99 & 0,65 & 63,9 & 0,99 \\
\hline & 85 & 0,73 & 19,8 & 0,99 & 0,63 & 80,1 & 0,99 & 0,68 & 58,7 & 0,99 \\
\hline \multirow[t]{4}{*}{356} & 25 & 0,56 & 148,3 & 0,99 & 0,72 & 32,9 & 0,99 & 0,68 & 105,5 & 0,99 \\
\hline & 45 & 0,59 & 112,7 & 0,99 & 0,76 & 20,7 & 0,99 & 0,71 & 91,7 & 0,99 \\
\hline & 65 & 0,63 & 100,2 & 0,99 & 0,80 & 16,1 & 0,98 & 0,76 & 85,4 & 0,99 \\
\hline & 85 & 0,67 & 87,0 & 0,99 & 0,83 & 12,4 & 0,99 & 0,78 & 70,2 & 0,99 \\
\hline
\end{tabular}



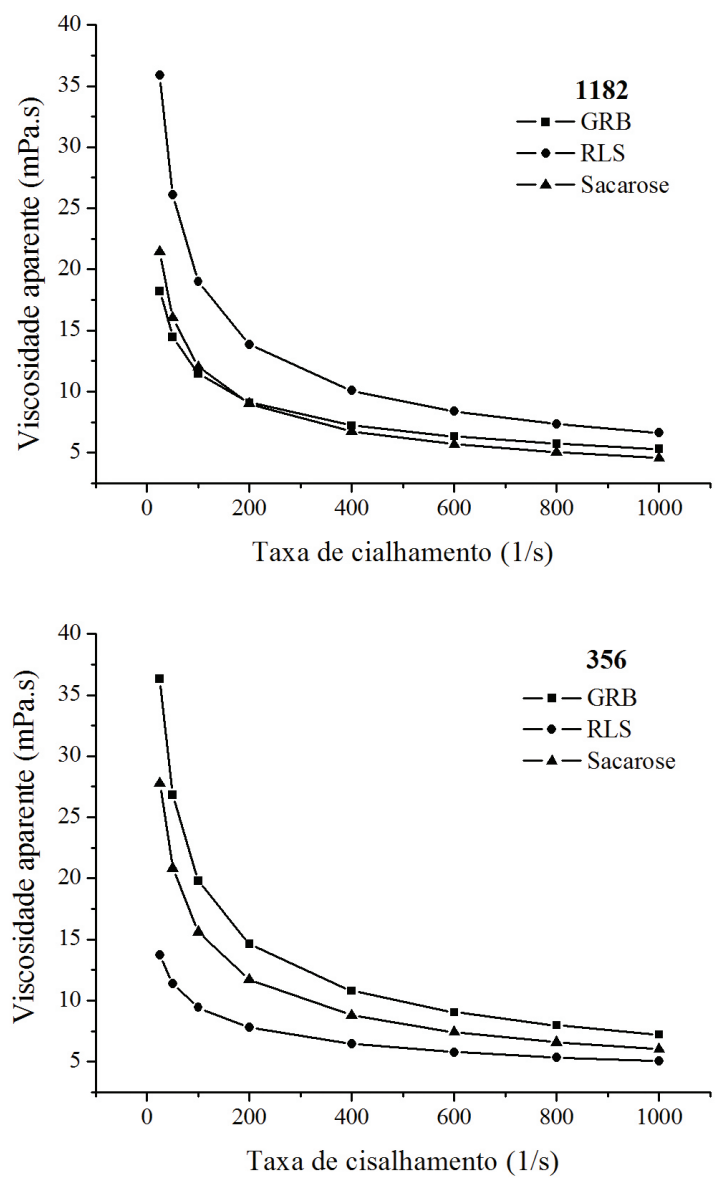

Figura 2. Taxa de cisalhamento $\mathrm{x}$ Viscosidade aparente $\left(25^{\circ} \mathrm{C}\right.$, $25 \mathrm{~s}^{-1}, 0,25 \% \mathrm{GX}(\mathrm{m} / \mathrm{v})$ das gomas xantana produzidas a partir de diferentes substratos pelas cepas 1182 e 356 de Xanthomonas.

seja, a cepa 1182 por fermentação do RLS produz uma goma de maior qualidade. $\mathrm{O}$ alto valor de $K$ é desejável para aplicação do polímero na área de alimentos, cosméticos e medicamentos, uma vez que resulta em menor quantidade do aditivo ${ }^{[3-14,15]}$, assim como, para fluidos de perfuração, pois alta viscosidade é necessária para manter em suspensão o cascalho gerado durante a perfuração ${ }^{[37]}$. Os coeficientes de correlação $\left(R^{2}\right)$ variaram entre 0,98 e 0,99 , mostrando que o modelo é valido, podendo ser usado na representação do comportamento das soluções de gomas. Portanto, pode-se avaliar o efeito tanto da cepa quanto do substrato fermentativo não somente na produção de GX (Tabela 1), na MM e no grau de conversão de cada substrato (Tabela 2), como também na viscosidade aparente (Figura 2), uma vez que as condições de fermentação foram idênticas em todas as fermentações. A máxima produção de GX foi obtida a partir da fermentação do resíduo RLS pelas cepas. A maior viscosidade foi apresentada pela GX resultante da fermentação da GRB com a cepa 356. A maioria das GX resultantes da fermentação dos rejeitos apresentaram duas frações de MM, sendo os maiores percentuais com MM superiores a $5,90 \times 10^{6} \mathrm{Da}$ e os menores variando entre 2,10 a $3,10 \times 10^{6} \mathrm{Da}$.

\section{Conclusões}

A produção de GX pelas cepas de Xanthomonas axonopodis pv. manihotis 1182 e $356 \mathrm{em}$ agitador orbital (250 rpm / $28{ }^{\circ} \mathrm{C} / 120 \mathrm{~h}$ ) por fermentação de sacarose (controle), glicerina residual do biodiesel e resíduo liquido de sisal (substrato alternativo), mostrou que tanto a composição dos rejeitos como as cepas exercem grande influência na produção, no consumo dos substratos, na viscosidade aparente e na massa molecular das gomas xantana resultantes, sem alterar o comportamento pseudoplástico das soluções aquosas dos biopolímeros. Isto representa uma possibilidade alternativa de bioconverter rejeitos agroindustriais de baixo custo em um produto de alto valor agregado.

\section{Agradecimentos}

Aos órgãos de fomento CAPES e FAPESB pelo apoio financeiro prestado

\section{Referências Bibliográficas}

1. Palaniraj, A.; Jayaraman, V. - J. Food Eng., 106, p.1 (2011). http://dx.doi.org/10.1016/j.jfoodeng.2011.03.035

2. Stankowski, J. D.; Muelle, R. B. E. \& Zeller, S. G. - Carbohydr. Res., 241, p.241 (1993).

3. Borges, C. D. \& Vendruscolo, C. T. - Semin., Cienc. Biol. Saude, 29, p.171 (2008).

4. Nery, T. B. R.; Brandao, L. V.; Esperidião, M. C. A. \& Druzian, J. I. - Quím. Nova, 31, p.1937 (2008). http:// dx.doi.org/10.1590/S0100-40422008000800004

5. Silva, M. F.; Fornari, R. C. G.; Mazutti, M. A.; Oliveira, D.; Padilha, F. F. \& Cichoski, A. J. - J. Food Eng. 90, p.119 (2009). http://dx.doi.org/10.1016/j.jfoodeng.2008.06.010

6. Aranda-Selverio, G.; Penna, A. L. B.; Campos-Sás, L. F.; Santos Junior, O.; Vasconcelos, A. F. D.; Silva, M. L. C.; Lemos, E. G. M.; Campanharo, J. C. \& Silveira, J. L. M. - Quím. Nova, 33, p.845 (2010).

7. Cadmus, M. C.; Knsuton, C. A.; Lagoda, A. A.; Pittsley, J. E. \& Burton, K. A. - Biotechnol. Bioeng, 20, p.1003 (1978). http://dx.doi.org/10.1002/bit.260200703

8. Kennedy, J. F. \& Bradshaw, I. J. - Program Ind. Microbiol., 19, p.319 (1984).

9. Borges, C. D.; Paula, R. C. M. D. E; Feitosa, J. P. A. \& Vendruscolo, C. T. - Carbohydr. Polym, 75, p.262 (2009). http://dx.doi.org/10.1016/j.carbpol.2008.07.013

10. Souw, P. \& Demain, A. - Appl. Environ. Microbiol, 37, p.1186 (1979).

11. Peters, H. U.; Suh, I. S.; Schumpe, A. \& Deckwer, W. D. - Biotechnol. Lett, 15, p.565 (1993). http://dx.doi. org/10.1007/BF00138540

12. Tako, M. \& Nakamura, S. - Agric. Biol. Chem, 48, p.2987 (1984). http://dx.doi.org/10.1271/bbb1961.48.2987

13. Kang, K. S. \& Pettit, D. J. - "Xanthan, gellan, wellan and rhamsan", in: Industrial gums, Academic Press, New York (1993). http://dx.doi.org/10.1016/B978-0-08-0926544.50017-6

14. Druzian, J. I. \& Pagliarini, A. P. - Cienc. Tecnol. Aliment, 27, p.26 (2007). 
15. Brandão, L. V.; Nery, T. B. R.; Esperidião, M. C. A. \& Druzian, J. I. - Polímeros. 20, p.175 (2010). http://dx.doi. org/10.1590/S0104-14282010005000029

16. Jana, A. K. \& Ghosh, P. - J. Ferment. Bioeng, 80, p. 485 (1995). http://dx.doi.org/10.1016/0922-338X(96)80924-X

17. Campos, M. I. - "Produção e caracterização de goma xantana obtida por bioconversão do resíduo líquido de sisal (Agave sisalana) em dois sistemas fermentativos", Dissertação de mestrado, Universidade Federal da Bahia, Brasil, (2010).

18. Diniz, D. M., Druzian, J. I., Audibert, S. Polimeros, 3, p.278. (2012). http://dx.doi.org/10.1590/S010414282012005000032

19. Yoo, S. D. \& Harcum, S. W. - Bioresource Technol, 70, p.105 (1999). http://dx.doi.org/10.1016/S0960-8524(99)00013-9

20. Costa, L. A. S. - "Biossíntese de Goma Xantana a partir da Casca de Camarão: Parâmetros de Fermentação e Caracterização do Biopolímero”, Dissertação de mestrado, Universidade Federal da Bahia, Brasil, (2010).

21. Felizardo, P. M. G. - "Produção de biodiesel a partir de óleos usados de frituras”, Monografia, Instituto Superior Técnico, Portugal, (2003).

22. Leoneti, A. B.; Aragão-Leoneti, V.; Oliveira, S. V. W. B. Renewable Energy, 45, p.138, (2012). http://dx.doi. org/10.1016/j.renene.2012.02.032

23. Sharapin, N. "Contribuição para o aproveitamento do sisal como fonte industrial de esteróides”, Tese doutorado, Universidade Federal Fluminense, Brasil (1980).

24. Bligh, E. G. \& Dyer, W. J. J. Can. J. - Biochem. Physiol., 37, p.911 (1957). http://dx.doi.org/10.1139/o59-099

25. Association of official analytical chemists. - "Official methods of analysis of AOAC International", 17th ed., Gaithersburg, 2000.
26. García-Ochoa, F.; Santos, V. E.; Casas, J. A. \& Gómez, E. - Biotechnol. Adv., 18, p.549 (2000). http://dx.doi. org/10.1016/S0734-9750(00)00050-1

27. Sutherland, I. W. - Biotechnol. Weinheim, 23, p.23 (1983).

28. Casas, J. A.; Santos, V. E. \& García-Ochoa, F. - Enzyme Microbiol. Technol., 26, p.282, (2000). http://dx.doi. org/10.1016/S0141-0229(99)00160-X

29. Brandão, L. V.; Nery, T. B. R.; Esperidião, M. C. A. \& Druzian, J. I. - Cienc. Tecnol. Aliment., 28, p.217 (2008). http://dx.doi.org/10.1590/S0101-20612008000500033

30. De Vuyst, L.; Van-Loo, J. \& Vandamme, E. J. J. - Chem. Technol. Biotechnol., 39, p.263 (1987). http://dx.doi. org/10.1002/jctb.280390407

31. Davidson, I. W. P. - Microbiol. Lett., 3, p.347 (1978). http:// dx.doi.org/10.1111/j.1574-6968.1978.tb01969.x

32. Nitschke M., Rodrigues V. \& Schinatto L. F. - Cienc. Tecnol. Aliment., 21, p.82 (2001). http://dx.doi.org/10.1590/ S0101-20612001000100018

33. Rosalam, S. \& England, R. - Enzyme Microb. Tech., 39, p.197 (2006). http://dx.doi.org/10.1016/j.enzmictec.2005.10.019

34. Rottava, I. - "Seleção de linhagens de Xanthomonas sp para produção de goma xantana", Dissertação de mestrado. Universidade Regional Integrada do Alto Uruguai e das Missões, Brasil (2005).

35. Torres, L. G.; Brito, E.; Galindo, E. \& Choplin, L. J. - Biotechnol. J. Biotechnol., 75, p.58, (1993).

36. Galindo, E. - Inst. Chem. Eng., 5, p.227, (1994).

37. Machado, J. C. V. - Reologia e Escoamento de Fluidos - Ênfase na Indústria do Petróleo", Interciência, Rio de Janeiro, 2002.

Enviado: 28/03/12 Reenviado: $10 / 01 / 13$ Aceito: 02/05/13 